\title{
ÁLBUNS FOTOGRÁFICOS DIGITAIS: ORGANIZAÇÃO, REPRESENTAÇÃO E PRESERVAÇẨO DA HERANÇA CULTURAL
}

\author{
ÁLBUMES FOTOGRÁFICOS DIGITALES: \\ CONTRIBUCIONES A LA CONSERVACIÓN DEL \\ PATRIMONIO CULTURAL
}

\author{
Ana Carolina Simionato* \\ Maria Lígia Triques** \\ Samanta do Prado*** \\ Amanda Azevedo dos Santos ${ }^{\star \star \star \star}$ \\ José Lotúmolo Junior ${ }^{\star \star \star * *}$
}

\begin{abstract}
RESUMO:
Introdução: Os avanços tecnológicos para o campo fotográfico trouxeram além de novas formas de composição, possibilidades para conexões entre indivíduos e suas vivências familiares ou individuais, desempenhando um papel importante no registro e na perpetuação da memória.

Objetivo: Objetiva-se a divulgar o uso de ferramentas para a composição de álbuns digitais com base nos princípios de organização e representação.

Metodologia: Apresenta uma pesquisa teórica e aplicada, qualitativa, a partir de uma revisão bibliográfica e de nível exploratório.

Resultados: Os álbuns digitais são ferramentas que os próprios usuários podem realizar os processos de organização e representação de imagens digitais, e auxiliam na preservação da herança cultural familiar.

Conclusões: Considera-se que os processos de tratamento informacional, por meio dos dados EXIF e de uma organização, as recordações e memórias familiares podem

*Doutora em Ciência da informação. Professora da Universidade Federal de São Carlos Ufscar.E-mail: simionato.ac@gmail.com

${ }^{* *}$ Graduando de Biblioteconomia e Ciência da Informação - UFSCar. E-mail: ligia.triques@gmail.com

*** Graduando de Biblioteconomia e Ciência da Informação - UFSCar. E-mail: samanta.prado21@gmail.com

**** Graduando de Biblioteconomia e Ciência da Informação - UFSCar. E-mail: amandahazevedo19@gmail.com

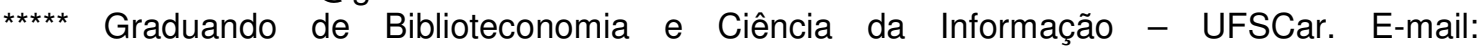
jolotuljunior@gmail.com
\end{abstract}


Ana Carolina Simionato, Maria Lígia Triques, Samanta do Prado, Amanda Azevedo dos Santos, José Lotúmolo Junior

Álbuns fotográficos digitais: organização, representação e preservação da memória familiar

ser preservadas, e utilizadas em outros tipos acervos de arquivos, bibliotecas e museus, considerando a pesquisa no seu escopo social para famílias e comunidades.

Palavras-chave: Álbuns fotográficos. Preservação da informação. Herança cultural.

\section{INTRODUÇÃO}

A produção de imagens acompanha a humanidade desde o princípio, com diferenças entre técnicas e expressões artísticas, incluindo pinturas, xilogravuras, desenhos, fotografia, entre outras formas de expressão. As imagens que no início tinham um valor quase sagrado, hoje se tornaram um meio de transmissão de ideias e valores, mas desde sua origem, a imagem é considerada como um meio de comunicação. No formato digital, as imagens são cada vez mais disseminadas com o uso de mídias sociais para compartilhamento.

No entanto, o ambiente digital trouxe novas soluções para 0 armazenamento e compartilhamento de arquivos digitais. Os núcleos familiares encontram na web plataformas como Facebook, Flickr, Instagram e blogs, como alternativas para o compartilhamento e acesso aos materiais individuais e coletivos. Nesse sentido, a construção de álbuns digitais tornou mais popular nos dias atuais, visto a agilidade que a câmera digital possui em ser visualizada em poucos segundos, e principalmente, a volatilidade de incluir e excluir a imagem.

Esses fatos tecem aprofundamentos teóricos e práticos para todas as áreas do conhecimento, inclusive a área de Ciência da Informação, que nesse caso, podemos ter conjunturas entre os campos da Arquivologia, Biblioteconomia e Museologia. Isso ocorre em razão do escopo em elucidar características de um documento imagético e suas proporções envoltas à forma em que foi criada essa imagem, sua organização, por exemplo, as famílias envolvidas e também, resgatar memórias e histórias e assim, dirigir ao estudo curatorial de um álbum familiar. 
Ana Carolina Simionato, Maria Lígia Triques, Samanta do Prado, Amanda Azevedo dos Santos, José Lotúmolo Junior

Álbuns fotográficos digitais: organização, representação e preservação da memória familiar

Nesse sentido, a preservação da herança cultural e reconstrução da história do individuo é um dos principais elementos da memória. A herança cultural, também encontrada com a expressão mais abrangente de 'patrimônio cultural', condiz a um conjunto de bens culturais, referentes às identidades coletivas atreladas à memória. Condiz ao estudo, o questionamento de preservar da herança cultural familiar por meio dos álbuns digitais?

Tendo em vista uma possibilidade para essa problemática, o estudo discute sobre a preservação das imagens digitais familiares e também, busca relacionar como representação e organizações de álbuns digitais podem contribuir para a preservação de ambientes digitais? Portanto, o objetivo do trabalho é promover o uso de ferramentas para composição de álbuns digitais com base nos princípios de organização e representação.

\section{A HERANÇA CULTURAL E OS ÁLBUNS DIGITAIS}

A fotografia é concebida pela captura de uma grande quantidade de raios na superfície da concentração em um ponto. O produtor da imagem e 0 receptor são os canais que intermediam este processo de transmissão estão sujeitas a interferências de amplos fatores. (AUMONT, 2002). Aumont (2002, p. 131) "[...] a imagem é também um meio de comunicação e de representação do mundo, que tem seu lugar em todas as sociedades humanas.".

Com o advento da fotografia em meados do século XIX, e posteriormente seu aperfeiçoamento até nos dias atuais, a imagem passa a ser um importante meio da fragmentação da realidade e de comunicação. Atribuindo seus usos à manipulação e outros comportamentos sociais, que vão do medo ao conhecimento defronte a uma determinada situação. "Imitadora, para um ela engana, para o outro ela educa. Desvia da verdade ou, pelo contrário, conduz ao conhecimento." (JOLY, 2006, p.19). Ainda que sejam possíveis interpretações individuais dos diversos aspectos envolvidos na captura e produção das imagens, a partir de questões subjetivas, culturais, temporais, até mesmo interesses materiais imediatos. 
Ana Carolina Simionato, Maria Lígia Triques, Samanta do Prado, Amanda Azevedo dos Santos, José Lotúmolo Junior

Álbuns fotográficos digitais: organização, representação e preservação da memória familiar

O significado da imagem pode ser assimilado de diferentes modos, e ser interpretado em diferentes contextos, religiosos, científicos, familiares e midiáticos, que tornam cada imagem como única. Outros paradoxos permeiam para subjetividade da memória, reprodutibilidade e autenticidade. No início, acreditava-se que a captura da fotografia era capaz de extrair a alma de um corpo, e com a popularização e comercialização das câmeras fotográficas, algumas famílias começaram a adotar esse tipo de registro como forma de perpetuidade e preservação de suas histórias.

As questões como reprodutibilidade e autenticidade de obras de arte foi o centro de inúmeras discussões. Alguns autores acreditam que a obra de arte sempre foi reprodutível, que os homens imitavam de seu mestre e em outros casos apenas para o lucro. "Em sua essência, a obra de arte sempre foi reprodutível. O que os homens faziam sempre podia ser imitado por outros homens." (BENJAMIN, 1992, p. 180).

Em seu discurso Benjamin (1992) expõe indagações a partir da reprodutibilidade da fotografia com a autenticidade da obra de arte. As lentes podem capturar belos ângulos da obra, podendo também aproximar um indivíduo a aquela obra, porém ela ficará guardada em um lugar qualquer. Sendo assim, ela perderá a sua admiração, e consequentemente a sua aura, que condiz "[...] uma figura singular, composta de elementos espaciais e temporais: a aparição única de uma coisa distante por mais perto que ela esteja." (BENJAMIN, 1992, p. 184).

O conceito de aura é atribuído às composições de obras de arte, e quando transpõem as indagações sobre sua essência, refletem em perspectivas para cada ambiente tradicional ou digital. Nesse sentido, a técnica para fotografia autoral busca independente de seu contexto, abrigar características que avalizam o olhar do fotógrafo, resgatando sua aura. Ao contrário da fotografia documental, que busca o olhar comprobatório e de perpetuidade da memória e da preservação da herança cultural. O seu valor documental, Felizardo e Samain (2007, p. 210) destacam que a fotografia 
Ana Carolina Simionato, Maria Lígia Triques, Samanta do Prado, Amanda Azevedo dos Santos, José Lotúmolo Junior

Álbuns fotográficos digitais: organização, representação e preservação da memória familiar

[...] foi agregado um elevado status de credibilidade devido à possibilidade de registrar partes selecionadas do mundo "real", da forma como "realmente" se apresentam. Assim, como a palavra fotografia, que do grego significa a "escrita da luz", a palavra memória também traz consigo traços de credibilidade, por evidenciar os fatos como se parecem, por mostrar os caminhos da lembrança.

O valor documental pode ser confirmado pelos acervos fotográficos dos meios de comunicação como jornais, revistas, instituições públicas e privadas e mesmo os acervos particulares e pessoais. A imagem registrada e estampada nos jornais sempre foi usada para chamar a atenção e se tornava um trunfo importante nas mãos de quem conseguia a única ou mesmo a melhor imagem do fato.

A partir dos primeiros registros fotográficos, logo começaram os estudos para encontrar métodos que pudessem aperfeiçoar o processo de captura, armazenamento e manipulação da imagem. Até que em 1969 foi criado o Charge-Coupled Device (CCD), em português Dispositivo de Carga Acoplada, que segundo Giacomelli (2012) permitem por meio de hastes microscópicas a captura da luz e a sua transformação de energia magnética em um arquivo eletrônico binário digital.

Apenas em 1989, iniciou o comércio das câmeras digitais fabricadas pela Fujifilm e vendida pelo preço de cinco mil dólares, com cartão de armazenamento de memória. Essa iniciativa despertou em outras empresas, como a Kodak a necessidade do desenvolvimento de câmeras para serem comercializadas.

Para a manipulação das imagens digitais foi necessário investimentos na área de softwares como Adobe Photoshop ou Gimp, como opção para open source ${ }^{1}$. Assim, o uso imagem digital começou a se popularizar, "Quando as câmaras digitais começaram a se popularizar, os profissionais da imagem já sabiam como manipulá-las no computador [...]" (GIACOMELLI, 2012, p. 58).

\footnotetext{
${ }^{1}$ Open source é uma expressão que refere ao código-fonte de um software, que pode ser adaptado para diferentes finalidades.
} 
Ana Carolina Simionato, Maria Lígia Triques, Samanta do Prado, Amanda Azevedo dos Santos, José Lotúmolo Junior

Álbuns fotográficos digitais: organização, representação e preservação da memória familiar

A partir desse cenário, as tecnologias ofereceram um crescente avanço para as técnicas imagéticas, fez com que os custos destas ferramentas e softwares diminuíssem tornando-se acessíveis à maioria da população. O que proporcionou uma grande facilidade para gerar imagens, e sua aceitação se tornou maior através das redes sociais "O século XXI inicia-se com a aceitação e utilização da imagem digital em ampla proporção, em grande parte devido à utilização das redes sociais [...]" (SIMIONATO, 2015, p. 40).

Independente de seus contextos, a fotografia digital ou tradicional, possuem processos diferentes, desde sua criação ao armazenamento. Por exemplo, a fotografia jornalística, da forma tradicional, depois de capturada, a imagem passa pela revelação do filme e depois, o editor escolhe a melhor, logo após, marca pelo diagramador e volta ao laboratório para a cópia final. No caso da digital o fotógrafo descarrega as imagens em um dispositivo podendo corrigir o brilho, cor em um software e em poucos minutos estará pronta para ser editada no jornal.

Além disso, com o advento das redes sociais a imagem digital tornou-se popular, pois em grande parte elas incentivam a criação e compartilhamento dessas imagens. O compartilhamento sem barreiras é alvo de discussões porque ela facilita o acesso, o que acabou levantando indagações sobre ética e autenticidade devido à facilidade de manipulação (GIACOMELLI, 2012).

O meio digital revitalizou as imagens e também os álbuns. Os álbuns representam o vínculo entre indivíduos e suas vivências familiares e individuais, desempenhando um papel importante no registro e na perpetuação da memória, pois trazem lembranças de experiências vividas, de lugares visitados, suas origens e uma trajetória de vida. Além disso, os álbuns fotográficos reajustaram para novas formas socioculturais de cada indivíduo. A

"[...] digitalização com processos mais simples e acessíveis a qualquer pessoa e a preocupação com a impressão em um papel fotográfico deixaram de existir com a intensidade que ocorria no processo de revelação das fotografias analógicas.". (SIMIONATO; PINHO NETO; SANTOS, 2015, p. 57). 
Ana Carolina Simionato, Maria Lígia Triques, Samanta do Prado, Amanda Azevedo dos Santos, José Lotúmolo Junior

Álbuns fotográficos digitais: organização, representação e preservação da memória familiar

A memória representa possibilidades de guardar o passado e é um saber criado e socialmente construído (HALBWACHS, 2006). Considerada mais ampla que as lembranças de um único indivíduo, a memória pode ser associada ao resgate e à preservação do passado social, um passado vivido coletivamente. No entanto, a memória não está ligada apenas ao passado, ela pode ser associada também ao presente e ao futuro.

Afinal, a memória influencia quem nós somos, o que fazemos e como agimos no mundo, portanto, ela influencia na construção do nosso futuro. Segundo Le Goff (2003, p. 419) "A Memória, como propriedade de conservar certas informações, remete-nos em primeiro lugar a um conjunto de funções psíquicas, graças às quais o homem pode utilizar impressões ou informações passadas, ou que ele representa como passadas.".

Esse conjunto de funções psíquicas não deve, no entanto, ser associado unicamente à memória individual. Esse processo de recuperação e representação do passado acontece a partir das funções cognitivas individuais, mas se desenvolve por meio das relações sociais. Le Goff (2003) destaca que a preservação da memória social é fundamental para a história, assim como todo o seu processo, seja de limitar ou de ampliar a informação.

Halbwachs (2006) aponta que a memória está localizada dentro de um determinado tempo e espaço. Entende-se por tempo não apenas as datas precisas, mas o período em que os acontecimentos ocorrem. De certa forma, o tempo de uma memória representa sua inscrição na história de vida ou na história social. Por sua vez, o espaço é o ambiente que nós frequentamos e pode conter uma variedade de histórias. (HALBWACHS, 2006).

A memória não se confunde com a lembrança, mas sim, está localizada dentro de um espaço e tempo de forma ampla. É realizada uma reconstrução de história e/ou de elementos de uma cultura, uma trajetória familiar ou um modo de vida. Já a lembrança é algo mais pontual e pessoal. Por exemplo, uma lembrança pode ser algo relacionado a um objeto, a um momento especifico. Uma memória individual pode ser feita de várias lembranças, mas uma lembrança isoladamente não constitui uma memória. 
Ana Carolina Simionato, Maria Lígia Triques, Samanta do Prado, Amanda Azevedo dos Santos, José Lotúmolo Junior

Álbuns fotográficos digitais: organização, representação e preservação da memória familiar

Em estudo sobre memória e identidade social, Pollak (1992) destaca os elementos constitutivos da memória, seja esta individual ou coletiva. $\mathrm{O}$ autor (POLLAK, 1992) indica algumas características gerais da memória, por fim, os elementos constitutivos da identidade, bem como algumas relações entre memória e identidade. Esse estudo possibilita estabelecer uma visão mais ampla a respeito do tema, e oferece algumas variáveis importantes para análise em pesquisas com memória.

Tanto para memória coletiva e individual, Pollak (1992) descreve três elementos que podem ser considerados componentes de toda memória, que são os acontecimentos, as personagens e os lugares. Cada um deles podem se apresentar na memória em formas diversas, em uma espécie de escala que engloba desde os aspectos mais próximos ao sujeito (vividos diretamente) até os aspectos mais distantes (de pano de fundo social ou histórico).

Os acontecimentos são basicamente os eventos que fazem parte de uma memória. Esses eventos podem ser públicos ou privados. Se pensarmos na memória como uma narrativa, os acontecimentos são as partes menores que compõem o enredo.

- O primeiro tipo de evento é aquele que engloba os acontecimentos vividos pessoalmente pelo sujeito. Ocorrências da vida pessoal, do cotidiano familiar, e da trajetória profissional são alguns exemplos. Esse tipo de memória se expressa quando o narrador faz relatos em primeira pessoa, revelando proximidade com os fatos narrados, na posição de testemunha direta dos acontecimentos. (POLLAK, 1992).

- $\quad$ O segundo tipo de evento é composto pelos acontecimentos vividos indiretamente, esses são os eventos vividos pelo grupo social ao qual o indivíduo pertence. Eles são "[...] acontecimentos dos quais a pessoa nem sempre participou, mas que, no imaginário, tomaram tamanho relevo que, no fim das contas, é quase impossível que ela consiga saber se participou ou não.". (POLLAK, 1992, p. 201). Aqui poderíamos incluir eventos familiares, de classe ou de grupo étnico, por exemplo, com maior ou menor grau de proximidade com relação ao sujeito da memória. Uma memória familiar pode 
Ana Carolina Simionato, Maria Lígia Triques, Samanta do Prado, Amanda Azevedo dos Santos, José Lotúmolo Junior

Álbuns fotográficos digitais: organização, representação e preservação da memória familiar

ser significativa o bastante para fazer parte da memória de um indivíduo, mesmo que este não tenha presenciado diretamente os acontecimentos referidos naquela memória. (POLLAK, 1992).

- $\quad U m$ terceiro tipo corresponde aos eventos mais distantes, que não estão contidos nos limites do espaço e do tempo vividos pelo narrador. "É perfeitamente possível que, por meio da socialização política, ou da socialização histórica, ocorra um fenômeno de projeção ou de identificação com determinado passado" (POLLAK, 1992, p. 201). Essa seria uma forma de memória herdada, com mais distanciamento entre 0 sujeito e os acontecimentos da memória. Um exemplo pode ser as memórias relativas ao país de origem dos colonos e imigrantes. Um indivíduo pode nunca ter morado ou visitado a nação de origem de sua família, mas determinadas memórias políticas ou históricas estão tão fortemente associadas à sua cultura e identidade, que são incorporadas em suas próprias memórias. (POLLAK, 1992).

Os personagens e os lugares da memória podem ser pensados em uma escala semelhante. Uma memória pode conter: personagens conhecidas ou encontradas diretamente pelo sujeito ao longo de sua vida; personagens relevantes dentro do grupo ou meio social ao qual o indivíduo pertence, ainda que não conhecidas diretamente; ou personagens mais distantes, dotadas de uma relevância política ou histórica que justifique sua participação nas memórias de indivíduos que nunca partilharam com elas o mesmo tempo ou espaço. (POLLAK, 1992).

Do mesmo modo, as memórias podem fazer referência: aos lugares diretamente conhecidos ou visitados pelo sujeito; aos lugares associados ao grupo social no qual o sujeito se insere; aos lugares nunca visitados, mas dotados de uma relevância política ou histórica, que justifique sua menção nas memórias individuais do sujeito narrador.

Por essas razões, as memórias podem ser compartilhadas, herdadas ou transferidas, e podem ser inclusive objeto de conflito entre diferentes sujeitos ou grupos sociais. As memórias podem apresentar intersecções entre as 
Ana Carolina Simionato, Maria Lígia Triques, Samanta do Prado, Amanda Azevedo dos Santos, José Lotúmolo Junior

Álbuns fotográficos digitais: organização, representação e preservação da memória familiar

esferas do público e do privado, e entre os níveis individual, local ou histórico. Elas podem ser apresentadas a partir de diferentes versões ou pontos de vista. Para além desses componentes básicos, as memórias apresentam uma série de características importantes, destacadas por Pollak (1992).

De certa forma, todos os componentes da memória destacados, podem estar presentes em uma fotografia. Além disso, cada fotografia pode conter significados mais próximos ou mais distantes das vidas pessoais de diferentes sujeitos. Elas podem ter relação com a vida familiar íntima, com um movimento ou acontecimento social ao qual o observador se sente fortemente ligado, ou a eventos da história que compõem o pano de fundo das vidas individuais.

Por meio das fotografias, podemos encontrar importantes contribuições para construção e reconstrução das memórias, individuais ou coletivas. Por meio das memórias, vão se construindo variadas versões da história, enriquecendo a descrição dos eventos com seus diversos pontos de vista. Diferentes identidades podem estar ligadas a uma mesma fotografia, bem como diferentes fotografias podem conter elementos de uma mesma identidade.

Devemos lembrar que a identidade social corresponde às formas como um indivíduo, um grupo ou uma sociedade percebe a si mesma e deseja ser reconhecida. (POLLAK, 1992). O pertencimento é uma marca de existência, de identificação de características próprias.

Podemos portando dizer que a memória é um elemento constituinte do sentimento de identidade, tanto individual como coletiva, na medida em que ela é também um fator extremamente importante do sentimento de continuidade e de coerência de uma pessoa ou de um grupo em sua reconstrução de si. (POLLAK, 1992, p. 05).

Dessa maneira, a identidade está fortemente ligada ao grupo familiar, os registros fotográficos constituem-se em um dos componentes relevantes que evidenciam esta relação.

Leite (1994) expõe como os álbuns de família ou as fotografias guardadas com carinho, mas sem muita ordenação, ou sem ordenação 
Ana Carolina Simionato, Maria Lígia Triques, Samanta do Prado, Amanda Azevedo dos Santos, José Lotúmolo Junior

Álbuns fotográficos digitais: organização, representação e preservação da memória familiar

alguma, podem reconstruir a trajetória de vida de muitas pessoas: os avós, até mesmo os bisavós, tios, sobrinhos, parentes mais distantes e amigos. Até mesmo as profissões podem ser deduzidas ou mesmo serem registradas diretamente. As festas, os momentos de felicidade, de comemoração, as ocasiões tristes e até as fúnebres, tudo isto pode ser encontrado, registrado subliminarmente nas imagens guardadas, em geral pela matriarca da família, nas palavras de Felizardo e Samain (2007, p. 213)

É importante salientar o papel da mãe como retratista e mantenedora das lembranças familiares. Pode-se até afirmar que é ela quem tem o papel e a preocupação em acompanhar o crescimento dos filhos, em preservar, organizar, catalogar as fotos, a memória fotográfica da família.

A organização de um álbum de família é a construção de um componente importante de nossa própria memória e, portanto de nossa própria identidade. $\mathrm{Na}$ medida em que organizamos um álbum desses estamos realizando uma organização de nossa própria identidade, com bem apontou Pollak (1992, p. 4-5)

Esse último elemento da memória - a sua organização em função das preocupações pessoais e políticas do momento mostra que a memória é um fenômeno construído. Quando falo em construção, em nível individual, quero dizer que os modos de construção podem tanto ser conscientes como inconscientes. O que a memória individual grava, recalca, exclui, relembra, é evidentemente o resultado de um verdadeiro trabalho de organização.

$\mathrm{Na}$ busca de informações sobre a data da foto, a data do evento registrado, o parente cujo nome não é lembrado, ou a pessoa desconhecida, muitas informações subjacentes ou periféricas acabam por ser somadas e um verdadeiro quebra-cabeça de nossas vidas. Pode ser que faltem algumas peças, ou que outras não se encaixem, mas sempre seremos nós, de alguma forma a sermos registrados ali.

Leite (1994, p. 135-136) expressa essa percepção,

Ao examinar uma fotografia, cada observador acaba sempre relacionando-a consigo, procurando discernir em si mesmo o 
Ana Carolina Simionato, Maria Lígia Triques, Samanta do Prado, Amanda Azevedo dos Santos, José Lotúmolo Junior

Álbuns fotográficos digitais: organização, representação e preservação da memória familiar

que talvez não percebesse sem a visão daquela imagem. A ânsia de se conhecer através do exame de retratos de família, principalmente, obedece a uma busca de identidade ligada aos desafios da metamorfose.

Ao visualizar uma determinada imagem ou fotografia, há a sensação de retornar àquele tempo e lugar, e se estiver conectada com a nossa história pessoal, ou sentimos curiosidade pela história das personagens e dos eventos envolvidos, ligados a certa época ou lugar, nos casos de um distanciamento maior. Nas fotografias, a memória é retratada pelo espaço e o tempo de cada imagem, pelas personagens que fizeram parte daquele momento, e pelos acontecimentos ali registrados.

\section{PROCEDIMENTOS METODOLÓGICOS}

Este estudo caracteriza como um estudo teórico e aplicado, pois busca compreender novas concepções de criação sobre as imagens digitais, propondo por meio dos álbuns digitais, formas para a organização e representação informacional. Também é considerado pela sua análise de resultados, caráter qualitativo e de nível exploratório.

A pesquisa foi realizada em três momentos:

- A importância da imagem digital como um recurso informacional que envolve subjetividades próprias e necessárias como uma herança cultural. A partir disso, foi discutido as características apropriadas a cada suporte e seus reflexos para conservação e preservação;

- $\quad \mathrm{Na}$ segunda etapa, foi compreendida a importância de um tratamento temático e descritivo adequado ao recurso informacional, por meio dos metadados e os dados Exchangeable Image File Format (EXIF);

- Na última parte foram confeccionados os álbuns digitais, onde cada integrante pode escolher qual ferramenta poderia utilizar, bem como 
Ana Carolina Simionato, Maria Lígia Triques, Samanta do Prado, Amanda Azevedo dos Santos, José Lotúmolo Junior

Álbuns fotográficos digitais: organização, representação e preservação da memória familiar

aquela que selecionada pelas opções web: Google Fotos $^{2}$ e Flickr $r^{3}$. Foram escolhidas essas duas ferramentas pela disposição visual das imagens e pela facilidade para o compartilhamento dos itens armazenados.

A pesquisa foi realizada em conjunto ao projeto de extensão "Representação e organização de imagens digitais como herança cultural" que reuni atividades de extensão e ensino, e pesquisa. Os integrantes do projeto por meio dos procedimentos adotados pela área de Ciência da Informação utilizaram de padrões de representação de imagens digitais e ainda, definiram formas de organização de álbuns digitais, com a finalidade de preservação de sua memória familiar.

É importante lembrar que as ferramentas escolhidas e utilizadas, atendem as necessidades de usuários comuns para a preservação e organização de suas imagens pessoais. No entanto, para necessidades maiores como o caso de instituições atreladas à memória, deve-se realizar um estudo de requisitos que consigam atender as necessidades mínimas da instituição.

\section{ORGANIZAÇÃO E REPRESENTAÇÃO DOS ÁLBUNS DIGITAIS}

Pelo contexto da Ciência da Informação, as imagens digitais abrangem um valor documental, mas, além disso, apresenta valores para memória do patrimônio cultural e comprovação de fatos. Como tal, as imagens e fotografias são entendidas como recursos informacionais que apresentam uma sintaxe informacional e que para serem localizados necessitam de registro

\footnotetext{
${ }^{2}$ Google Fotos está disponível pelo link: <https://www.google.com/photos/about/?hl=pt-BR $>$.

${ }^{3}$ Flickr está disponível em: <https://www.flickr.com/>.

${ }^{4}$ Projeto de extensão: Representação e organização de imagens digitais como herança cultural (23112.001685/2015-34) realizado no período de agosto a dezembro de 2015, possui o objetivo de possibilitar formas interdisciplinares para organização e tratamento de imagens para álbuns digitais, elucidando a representação e organização de imagens a fim da preservação e memória dos álbuns familiares.
} 
Ana Carolina Simionato, Maria Lígia Triques, Samanta do Prado, Amanda Azevedo dos Santos, José Lotúmolo Junior

Álbuns fotográficos digitais: organização, representação e preservação da memória familiar

informacional, descrição e orientações precisas e específicas para seu tratamento descritivo. (SIMIONATO; SANTOS, 2013).

A representação e a organização são processos ligados ao tratamento e análise dos recursos informacionais. Nesse sentido, como expõe Simionato e Santos, "As orientações para o tratamento descritivo informacional compreendem a análise sistemática e a descrição dos elementos de uma imagem para sua identificação, localização, acesso e recuperação.". (SIMIONATO; SANTOS, 2013).

Nesse sentido, destaca-se a importância da construção de representações em que as informações estejam devidamente estruturadas e descritas para tornar os recursos acessíveis e recuperáveis. De tal modo, a importância dos metadados para a construção de formas de representação é fundamental. Os metadados, para o escopo da Ciência da Informação têm como principal objetivo a descrição da informação para sua representação, busca e recuperação. No contexto da representação da informação, os metadados atuam como referenciais ao que é representado e como intermediário entre o objeto representado e o usuário. (FUSCO, 2010). Ainda, conforme apontado por Baca (2008), os metadados e padrões de metadados estipulam maneiras padronizadas que podem auxiliar no acesso e localização do material informacional e contribuir para organização, além possibilitar a preservação.

Assim, a função dos padrões de metadados é possibilitar a padronização da representação recursos informacionais, aumentando as formas de acesso ao recurso, visando os processos de busca, localização e recuperação, entre outras funções. Nesse sentido, os conjuntos de metadados são a chave na busca para organização e representação dos recursos imagéticos digitais, pois são dados que referenciam o recurso possibilitando sua organização e preservação, através da representação.

Devido a grande preocupação com a ética e autenticidade da imagem, foram desenvolvidos softwares que marcam a imagem para que ela não seja manipulada e se percam os direitos autorais sobre ela. Alguns destes softwares 
Ana Carolina Simionato, Maria Lígia Triques, Samanta do Prado, Amanda Azevedo dos Santos, José Lotúmolo Junior

Álbuns fotográficos digitais: organização, representação e preservação da memória familiar

alteram os metadados, que podem ser localizados e utilizados com facilidade pela internet, neles o autor das imagens pode colocar dados sobre a imagem.

Um importante fator na representação e descrição dos recursos informacionais imagéticos, são as estruturas ou esquemas de dados automáticos, os dados Exchangeable Image File Format (EXIF). Segundo Simionato (2012), os dados EXIFs são "[...] informações técnicas de captura da imagem gravadas junto ao arquivo da imagem na forma de metadados etiquetados.", ou seja, são dados que são gravados junto ao arquivo da imagem no momento da captura, que representam informações sobre as condições da imagem, ou como Silva (2015) coloca, os dados em formato EXIF são informações acopladas às fotografias digitais e que são geradas pela câmera que captura a imagem.

No cenário da produção contemporânea de imagens digitais, um importante fator é a capacidade das imagens digitais portarem informações próprias, ou como aponta Silva (2015),

[...] o fato de que toda fotografia digital é hoje capaz de portar dados e informações, os ditos metadados, que vão bem além daquelas informações correspondentes à luminosidade que compõe a imagem visível, e que tem um grande potencial de propulsionar seu potencial informativo.

Nesse sentido, ferramentas que possibilitam o controle dos dados EXIF são fundamentais para o registro da informação digital como a EXiFTool. A figura 1 dispõe sobre o uso dos metadados EXIF no Google Fotos e no Flickr. 
Ana Carolina Simionato, Maria Lígia Triques, Samanta do Prado, Amanda Azevedo dos Santos, José Lotúmolo Junior

Álbuns fotográficos digitais: organização, representação e preservação da memória familiar
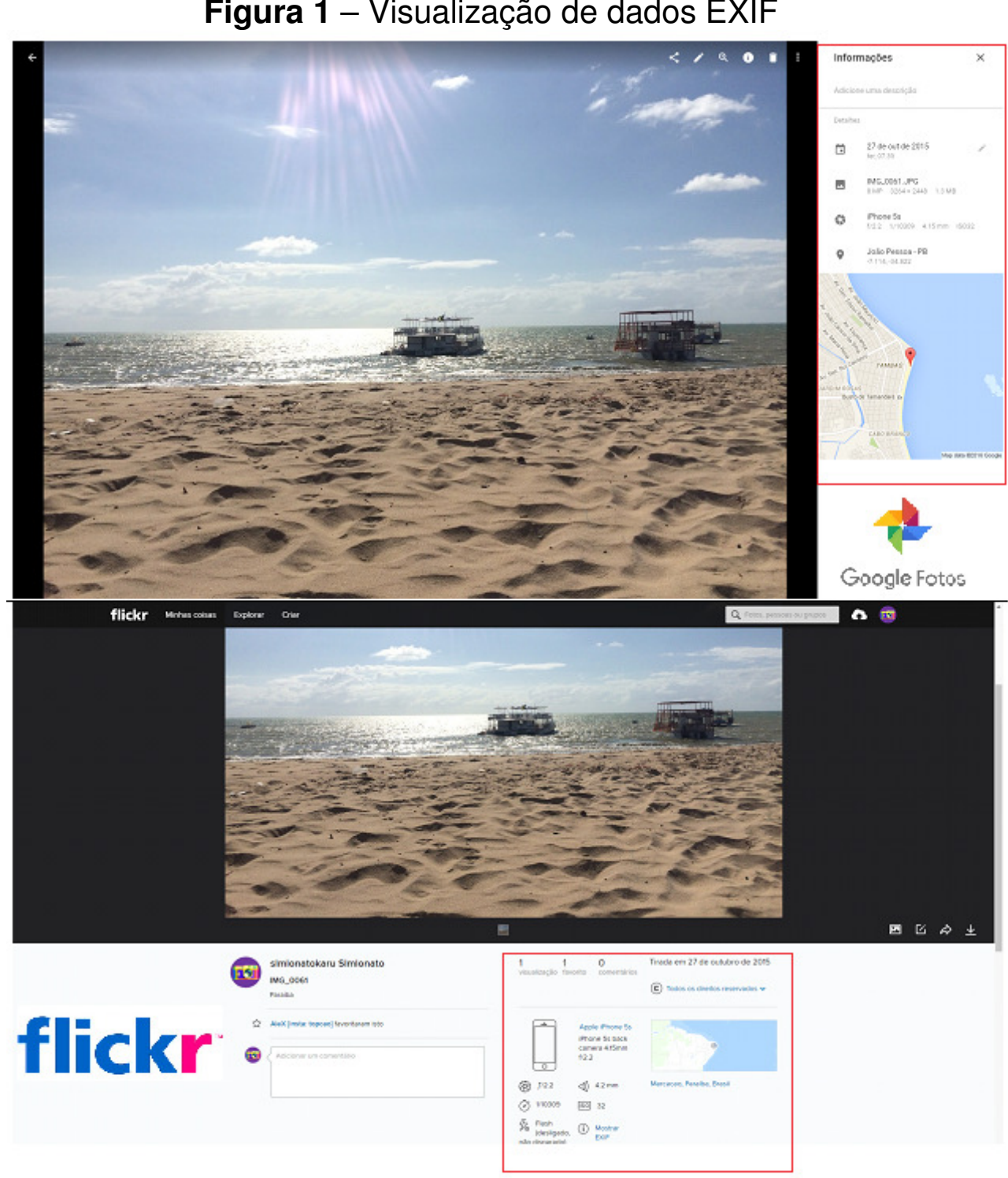

Fonte: Elaborado pelos autores.

Como apresentado na figura 1, por meio dos metadados automáticos é que os arquivos imagéticos ganham uma representação, como por exemplo, a identificação de data de registro do recurso, o dispositivo que gerou a imagem ou demais informações referentes ao momento da captura, além de informações que podem ser atribuídas pelo próprio usuário do recurso.

Diante disso, a representação e a organização de imagens digitais ganham um grande destaque na sociedade atual, frente às indefinidas proporções de recursos imagéticos gerados diariamente. Tais recursos são em 
Ana Carolina Simionato, Maria Lígia Triques, Samanta do Prado, Amanda Azevedo dos Santos, José Lotúmolo Junior

Álbuns fotográficos digitais: organização, representação e preservação da memória familiar

muitos casos gerados indefinidamente e sem qualquer preocupação quanto a sua identificação ou descrição, ou mesmo sem que o usuário detentor da imagem tenha conhecimento da necessidade desse tratamento ou dos meios de fazê-lo.

Nessa perspectiva, tal realidade acaba por configurar um grande desafio no momento de lidar com esse conteúdo imagético em meio digital. O desconhecimento dos processos de tratamento informacional, ou mesmo o não entendimento da necessidade de que todos os recursos imagéticos tenham sua representação, implica muitas vezes em grandes dificuldades no momento posterior de localização e acesso. Além disso, a própria complexidade na representação acaba por agravar ainda mais essa situação. Diante disso, Simionato e Santos (2013, p. 05), apresentam que,

[...] as questões-chave na representação da imagem digital são a concepção, a implementação, a definição de metadados e a representação dos valores de cada atributo, muitos deles com o preenchimento no momento de extração de imagens e elaborado dinamicamente de acordo com impressão do usuário e a captura de conteúdo, uma vez que o conteúdo imagético é correlato a várias interpretações.

Como as autoras colocam, a representação consiste em definir os metadados e os valores das informações a serem atribuídas aos recursos, no entanto, no caso das imagens digitais, esse processo muitas vezes ocorre no memento da extração automática das imagens da máquina que a capturou, sem a preocupação de que os dados atribuídos representem efetivamente 0 objeto digital referente.

Simionato e Santos (2013, p. 02) ainda explicam que

[...] as orientações para a descrição do material imagético digital precisam considerar as especificidades desse tipo de recurso, que em muitos casos são o que mais consiste a dificuldade do registro e de modo que a sintaxe da imagem digital seja explicitada pelos esquemas de descrição como requisito para sua representação.

Em outras palavras, as informações que referenciam o objeto digital precisam representá-lo da forma correta, tendo em vista suas características 
Ana Carolina Simionato, Maria Lígia Triques, Samanta do Prado, Amanda Azevedo dos Santos, José Lotúmolo Junior

Álbuns fotográficos digitais: organização, representação e preservação da memória familiar

inerentes. Sem essa devida conexão entre a representação atribuída e o objeto, a ligação entre esse objeto e o usuário não se efetiva, implicando em diversos problemas de recuperação e localização, e muitas vezes até de perda desses recursos em meio a uma vasta gama de outros recursos.

$\mathrm{Na}$ última parte foram confeccionados os álbuns digitais, cada integrante do projeto elencou fotografias expressivas para sua história, e compôs o álbum digital. Cada aluno pode escolher qual ferramenta poderia utilizar, bem como aquela que selecionada pelas opções web: Google Fotos e Flickr. A figura 2 mostra uma parte de um álbum ${ }^{5}$, com algumas fotografias históricas da família do aluno.

Figura 2 - Apresentação inicial do álbum de família pelo Google Fotos

\section{Álbum de Família}

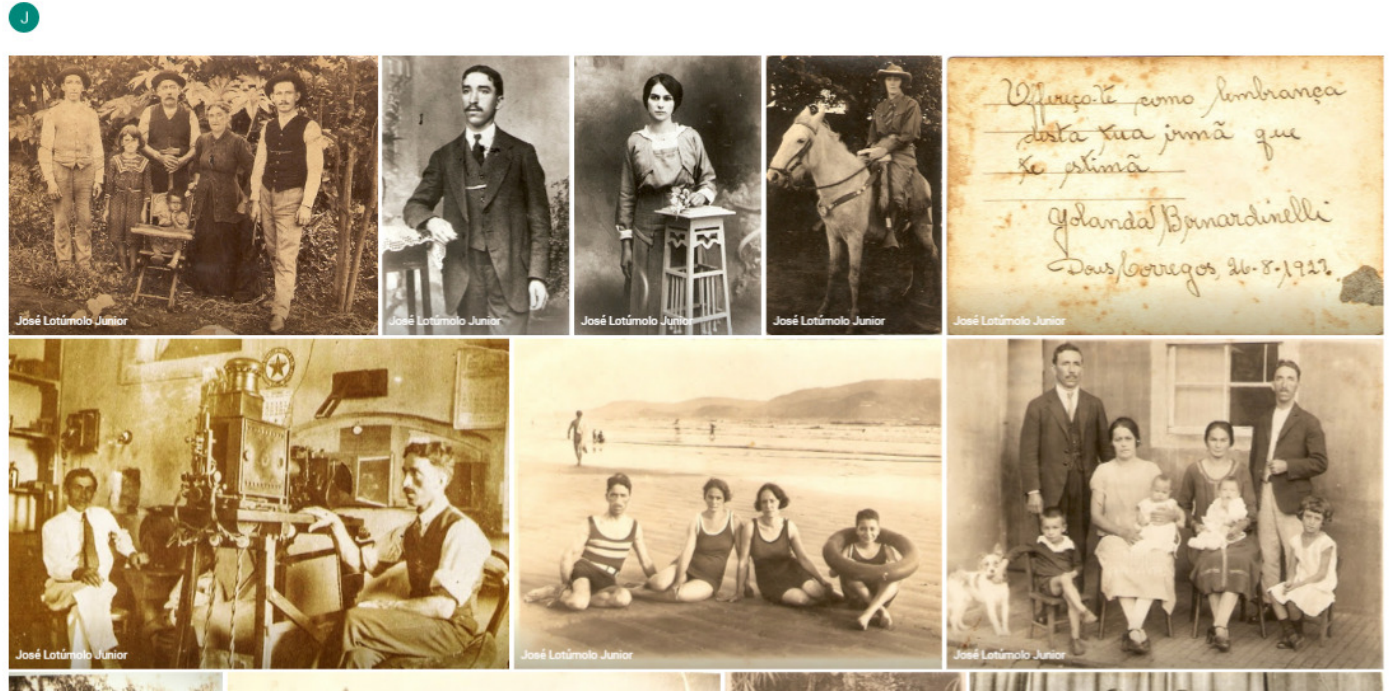

Fonte: LOTÚMULO JÚNIOR, 2015.

5 Álbum digital de LOTÚMULO JÚNIOR, J. Álbum familiar. 2015. Disponível em: $<$ https://goo.gl/nrn3p8 >. Acesso em: 20 fev. 2016. 
Ana Carolina Simionato, Maria Lígia Triques, Samanta do Prado, Amanda Azevedo dos Santos, José Lotúmolo Junior

Álbuns fotográficos digitais: organização, representação e preservação da memória familiar

O preenchimento de metadados pelo EXiFTool para fotografias digitalizadas, e propiciam à própria ferramenta de criação de álbuns digitais coordenadas para organização em datas e temas. Ao contrário da visualização que o Flickr apresenta como visualizado pela figura 3.

Figura 3 - Apresentação do álbum ${ }^{6}$ no Flickr

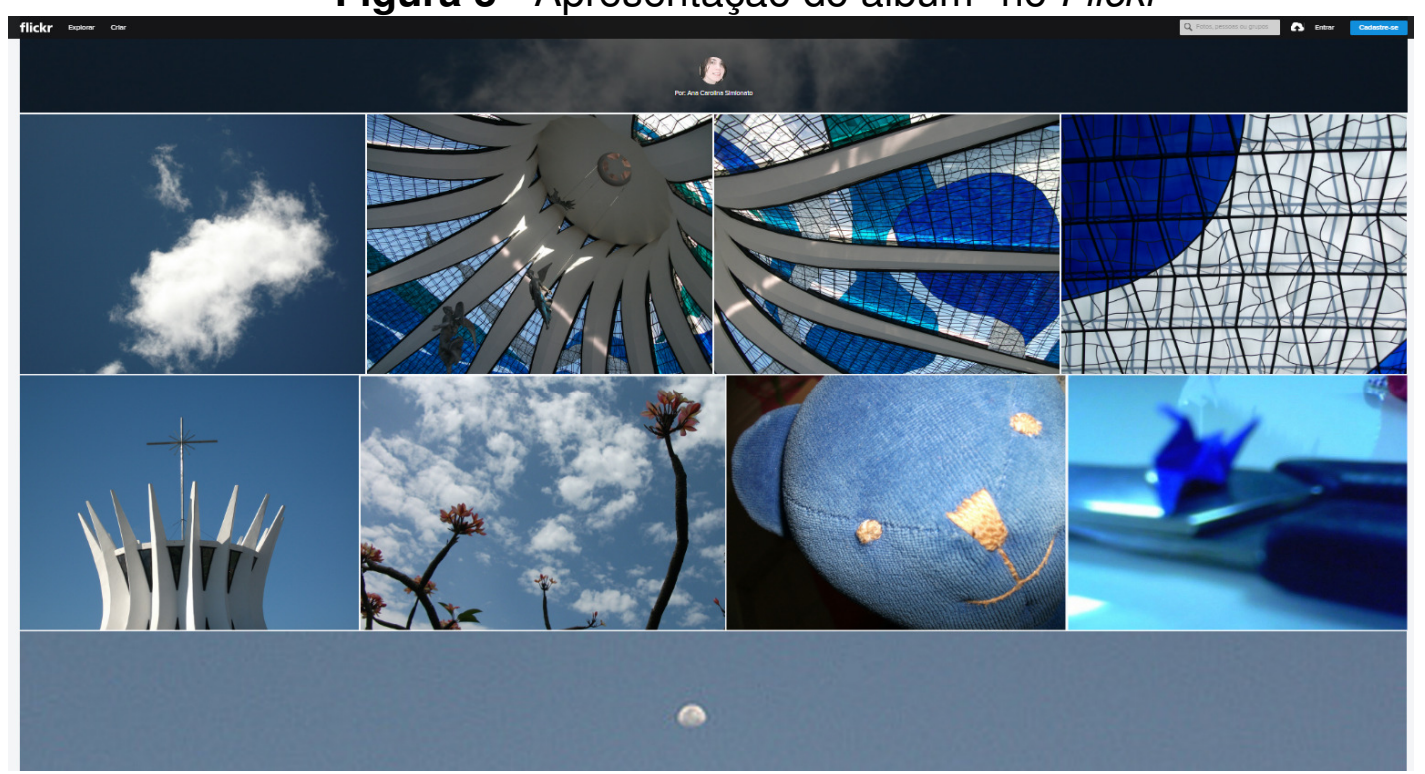

Fonte: SIMIONATO, 2016.

Em comparação entre as ferramentas e os serviços disponíveis aos usuários, verifica-se que as formas organizacionais o Flickr apresenta maior flexibilidade, sendo disponível 'Coleção' que abriga a vários 'Álbuns', e também é possível realizar uma 'Exposição', com as fotos favoritas por um período de tempo escolhido pelo usuário. Já o Google Fotos possui de maneira mais dinâmica e intuitiva para a composição dos álbuns, podendo criar 'Histórias', 'Colagem' e 'Animação'. Para as edições da imagem, ambas as ferramentas estão disponibilizadas. A visualização dos dados EXIF também é permitida em ambas as plataformas. O compartilhamento entre usuários é permitido somente

\footnotetext{
6 Álbum digital SIMIONATO, A. C. Disponível em:
} $<$ https://www.flickr.com/photos/karusimionato/albums/72157628131010933>. 
Ana Carolina Simionato, Maria Lígia Triques, Samanta do Prado, Amanda Azevedo dos Santos, José Lotúmolo Junior

Álbuns fotográficos digitais: organização, representação e preservação da memória familiar

com o Google Fotos, sendo permitida a inclusão de novas imagens, mobilidade entre os álbuns e exclusão das imagens.

Para as imagens digitais, a definição do conteúdo dos metadados e a representação de cada campo de descrição são além de ser uma chave para a organização e recuperação, são fundamentos para a preservação, proporciona mais dinamicidade ao álbum digital.

\section{CONSIDERAÇÕES FINAIS}

Considera-se que as diversas ferramentas do ambiente digital oferecem armazenamento para as imagens digitais, no entanto, sem a disposição de um ambiente especificamente preparado para que o usuário confeccionar seus álbuns digitais. A falta de preparo dos usuários para as ferramentas, resulta na dificuldade de acesso e de processos para preservação desses materiais ao longo do tempo. A escolha da organização dos álbuns de família sob o formato digital levou em conta fatores como a possibilidade de prolongar o tempo de vida da imagem, especialmente se ele foi produzido originalmente no formato analógico e transposto para o ambiente digital.

Entre os benefícios para a construção do álbum diretamente nas ferramentas que hoje podemos encontrar, como: Google Fotos, Flickr, entre outros. Caso as imagens, ou algumas delas, têm sido produzidos no formato analógico acrescentar-se-á somente mais um passo, ou seja, a digitalização das mesmas, igualando todos os formatos finais.

As ferramentas existentes hoje permitem a edição das imagens, que oferecem recursos para que redimensione, ou recorte, ou altere a coloração, entre outras opções que reparam defeitos e desgastes do tempo. Aqui, inferese que não se trata de mascarar a realidade em relação aos ajustes dos recursos, embora este objetivo também possa ser alcançado. No entanto, há que se reconhecer que as imagens que antes poderiam não ser consideradas aproveitáveis para determinadas finalidades, acabam por ser mais bem aproveitadas com a utilização destes recursos. Como também, deve-se levar em conta que a popularização das câmeras digitais e dos recursos 
Ana Carolina Simionato, Maria Lígia Triques, Samanta do Prado, Amanda Azevedo dos Santos, José Lotúmolo Junior

Álbuns fotográficos digitais: organização, representação e preservação da memória familiar

informacionais popularizou também este trabalho de melhoria das imagens. É, em muitos casos, o próprio criador das imagens quem trabalha as fotos e que produz os álbuns.

Por conseguinte, as finalidades da atividade desenvolvida, buscou selecionar as imagens, entre tantas disponíveis nos arquivos pessoais de cada um dos autores.

A escolha das fotografias recordou e apresentou sentimentos e subjetividades, muitas vezes imperceptíveis em um primeiro momento, mas que revelam uma relação com as pessoas e cenários representados, que seguramente dizem muito a cada um dos participantes. Embora não seja objeto deste estudo esta situação foi percebida por todos, posteriormente.

A popularização da produção de imagens por meios digitais através de celulares e smartphones é um fator importante na produção da herança cultural das sociedades. Hoje qualquer pessoa pode fotografar, não sendo mais uma atividade restrita a poucos iniciados. $\mathrm{O}$ ato de fotografar já não está restrito à muitas regras, que embora sejam importantes, corretas e tenham sua razão de ser, pareciam distanciar os fotógrafos das demais pessoas. Hoje qualquer pessoa, de qualquer condição social fotografa.

O grande desafio é saber o que e como fazer para conservar este imenso volume de imagens geradas em vários formatos. Por essa razão, destaca-se a importância do planejamento e estudo dos novos ambientes para o armazenamento e perpetuidade da herança cultural de pessoas, famílias instituídas em acervos de arquivos, bibliotecas e museus. Conclui-se ainda, que é uma área promissora para o profissional da informação, que têm competências e habilidades para realizar e criar um sistema de organização e representação para um conjunto de fotografias, possibilitando otimizar a recuperação desses recursos informacionais. Bem como, a importância destas atividades de pesquisa que se relacionam ao seu escopo social para famílias e comunidades.

Agradecemos o apoio da: Pró Reitoria de Extensão da Universidade Federal de São Carlos - Proex UFSCar, processo 23112.001685/2015-34. 
Ana Carolina Simionato, Maria Lígia Triques, Samanta do Prado, Amanda Azevedo dos Santos, José Lotúmolo Junior

Álbuns fotográficos digitais: organização, representação e preservação da memória familiar

\section{REFERÊNCIAS}

AUMONT, J. A imagem. Campinas: Papirus, 2002.

BACA, M. (Ed.) Introduction to metadata. Los Angeles: Getty Publications, 2008.

BENJAMIN, W. A obra de arte na era de sua reprodutibilidade técnica. In: BENJAMIN, W. Sobre arte, técnica, linguagem e política. Lisboa: Antropos, 1992. p. 166-196.

BORKO, H. Information science: what is it?. American documentation, v. 19, n. 1, p. 3-5, 1968.

FELIZARDO, A.; SAMAIN, E. A fotografia como objeto e recurso de memória. Discursos fotográficos, v. 3, n. 3, p. 205-220, 2007. Disponível em: $<$ http://www.uel.br/revistas/uel/index.php/discursosfotograficos/article/view/1500 $>$. Acesso em: 30 jun. 2016.

FUSCO, E. Modelos conceituais de dados como parte do processo da catalogação: perspectiva de uso dos FRBR no desenvolvimento de catálogos bibliográficos digitais. 2010. Tese (Doutorado em Ciência da Informação)Faculdade de Filosofia e Ciências, Universidade Estadual Paulista "Júlio de Mesquita Filho", Marília, 2010. Disponível em: <http://www.marilia.unesp.br/Home/Pos-Graduacao/Cienciadalnformacao /Dissertacoes/fusco_e_do_mar.pdf>. Acesso em: 25 jun. 2016.

GIACOMELLI, I. L. A transição tecnológica do fotojornalismo: da câmara escura ao digital. Florianópolis: Insular, 2012.

HALBWACHS, M. A memória coletiva. Trad. de Beatriz Sidou. São Paulo: Centauro, 2006.

JOLY, M. Introdução à análise da imagem. Campinas: Papirus, 2006.

LE GOFF, J. História e Memória. Campinas, Unicamp, 2008.

LEITE, M. M. Retratos de família: leitura da fotografia histórica. São Paulo: Edusp, 1994.

POLLAK, M. Memória e identidade social. Estudos históricos, v. 5, n. 10, p. 200-212, 1992.

SILVA, W. S. O estatuto documental da fotografia na era digital.

Artciencia.com, n. 19, 2015. Disponível em: <http://www.artciencia.com/index.php/artciencia/article/view/516>. Acesso em: 28 mai. 2016. 
Ana Carolina Simionato, Maria Lígia Triques, Samanta do Prado, Amanda Azevedo dos Santos, José Lotúmolo Junior

Álbuns fotográficos digitais: organização, representação e preservação da memória familiar

SIMIONATO, A. C. Modelagem conceitual DILAM: princípios descritivos de arquivos, bibliotecas e museus para o recurso imagético digital. 2015. $200 \mathrm{f}$. Tese (Doutorado em Ciência da Informação)- Universidade Estadual Paulista "Júlio de Mesquita Filho", Marília/SP, 2015. Disponível em:

<http://www.marilia.unesp.br/Home/Pos-

Graduacao/Cienciadalnformacao/Dissertacoes/simionato_ac_do_mar.pdf>.

Acesso em: 28 mai. 2016.

SIMIONATO, A. C.; PINHO NETO, J. A. S.; SANTOS, P. L. V. A. C. Ciência da Informação, Imagem e Tecnologia. Informação \& Tecnologia, v. 2, n. 1, p. 5365, 2015. Disponível em:

<http://periodicos.ufpb.br/ojs/index.php/itec/article/view/25984>. Acesso em: Acesso em: 28 mai. 2016.

SIMIONATO, A. C.; SANTOS, P. L. V. A. C. Descrição de recursos imagéticos digitais: apresentação de um modelo conceitual. Anales de Documentación, vol. 16, n. 2, 2013. Disponível em:

<http://revistas.um.es/analesdoc/article/view/179261>. Acesso em: 28 mai. 2016.

Title

Digital photo albums: organization, representation and preservation of cultural heritage Apresentar o título em inglês (para textos em português e espanhol)

Abstract:

Introduction: The technological advancements to the photographic field brought in addition to new forms of composition, possibilities for connections between individuals and their family or individual experiences, playing an important role in the registry and on the perpetuation of the memory.

Objective: the goal is to promote the use of tools for the composition of digital albums based on the principles of organization and representation.

Methodology: Presents a theoretical and applied research, qualitative, from a literature review and exploratory level.

Results: The digital albums are tools that the users themselves can carry out the processes of organization and representation of digital images, and assist in the preservation of family heritage.

Conclusions: the informational processes, using the EXIF data and of an organization, the memories and family memories can be preserved, and used in other types of collections archives, libraries and museums, whereas the social scope your search to families and communities.

Keywords: Photo albums. Information preservation. Cultural heritage. 
Ana Carolina Simionato, Maria Lígia Triques, Samanta do Prado, Amanda Azevedo dos Santos, José Lotúmolo Junior

Álbuns fotográficos digitais: organização, representação e preservação da memória familiar

\section{Titulo}

Álbumes fotográficos digitales: contribuciones a la conservación del patrimonio cultural

Resumen:

Introducción: Los avances tecnológicos en el campo fotográfico que además nuevas formas de composición, las posibilidades de conexiones entre los individuos y sus experiencias familiares o individuales, jugando un papel importante en el registro y en la perpetuación de la memoria.

Objetivos: El objetivo es promover el uso de herramientas para la composición de álbumes digitales, basado en los principios de organización y representación. Metodología: Se presenta una investigación teórica y aplicada, cualitativa, desde un nivel exploratorio y revisión de la literatura.

Resultados: Los discos digitales son herramientas que los propios usuarios pueden llevar a cabo los procesos de organización y representación de imágenes digitales y ayudar en la preservación del patrimonio familiar.

Conclusiones: Los procesos informativos, utilizando los datos EXIF y de una organización, los recuerdos y memorias de la familia pueden ser preservados y utilizados en otros tipos de archivos de colecciones, bibliotecas y museos, mientras que el social alcance su búsqueda a las familias y comunidades.

Palabras clave: Álbumes de fotos. Preservación de la información. Patrimonio cultural.

Recebido: 10.03.2017

Aceito: 10.11.2017 